\title{
Disaster management base on geoinformatics
}

\begin{abstract}
Disasters including natural and manmade make heavy losses in life and property each year. This subject can affect society, economy, and environment and can be a serious threat for development. In 10 years ago over 200 million people are have been effected both life and property. This figure is seven times more than losses in war. After the earthquake in Bam (a city in south Iran), tsunami in south-eastern of Asia, fire in Australia, and other disasters, the management of disaster has been considered more than before. They have tried to use all facilities and equipment for reduction of disaster damage. Over $80 \%$ of necessary data in disaster management are spatial data. The applications of geoinformatics technology products particularly derived from space earth observation satellite and remote sensing integrated with GIS technology to various areas of earth sciences, urban management, geohazards, mapping, planning, early warning system and development has been highly rewarding. Spatial data and advanced technologies have an important role in disaster management because Geographic Information System (GIS) can help in identifying disaster points. GIS combines geospatial data, and hardware, software that can analyze data to Produce information. GIS mainly involves saving and analysis of data according to spatial and attribute data. GIS can combine and analyze spatial and non-spatial data. We have made an attempt to consider disasters management according to facilities and role of Geospatial Technology in control of disaster (especially earthquake).
\end{abstract}

Keyword: Management of disaster; Geospatial; Earthquake; 3D GIS 